\title{
Grid Connected Energy System four leg Inverter for DC Voltage and Power Improvement
}

\author{
Yogeeta Hurde \\ M.Tech Scholar \\ LNCT, Bhopal
}

\begin{abstract}
The first power systems were DG systems designed to meet the needs of local areas.Full load DG applications showed greater benefits in terms of power and performance as well as reducing transmission losses. GDs are very suitable for a specific location and for specific applications because they require a short construction time and require little investment. It is defined on the basis of the size of the plant, which can vary from a few $\mathrm{KW}$ to MW (10-50 MW). GD options can be classified as renewable or non-renewable sources from fuel sources. This study deals with a newly-conceived voltage control method for three-phase four-leg voltage source inverters (VSIs) which are being required in autonomous power generating units devoted to supply both three-phase and single-phase electrical loads
\end{abstract}

Keywords: Energy storage systems [ESS], four-leg inverter, LC filter

\section{INTRODUCTION}

Energy is a fundamental and critical component in modern global economy. It is used by industries and household residents as one of the

basic need of life. Today about $87 \%$ of global energy is supplied through three primary sources that include oil, coal and natural gas [1]. These fossil fuels have limited lifespan and are available only in certain regions. According to

some latest statistics, global reserves for coal, oil and gas have only lifespan of 112, 63.6 and 54.2 years respectively $[2,3]$. About 1.3 billion people in the world still do not have access to electricity today, and more than 2.6 billion rely on traditional biomass for cooking and heating [4]. Meanwhile global energy consumption is projected to increase by more than 56 $\%$ in 2040 [5].

Energy storage systems are reported to be of short, medium to long scale sizing to cope with various

\author{
Nandkishor \\ Assistant Professor \\ LNCT, Bhopal
}

applications in power system [6,7]. As utilization of renewable sources creates concern about fluctuation of different power parameters which may also lead to damage of equipment other than power quality issues [8]. ESSs can support in restoration of low voltages by providing required reactive power to networks and let thermal generators to follow scheduled generation to supply as per base loads [9]. ESSs have also been favorable to improve the power quality in addition storage un-served electricity.

A. Renewable energy resources

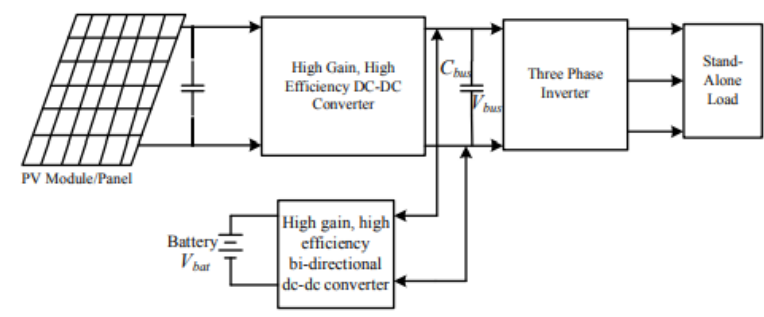

Figure 1: Simplified block diagram of the complete PV system

\section{B. Photovoltaic Array}

Again, the power generated by a single module is not sufficient to meet performance requirements for most practical purposes. PV Molds These inverters can be used to convert the DC output into AC and use it for motors, lighting and other loads. The modules are connected in series for more voltage and then in parallel to meet the current specifications.

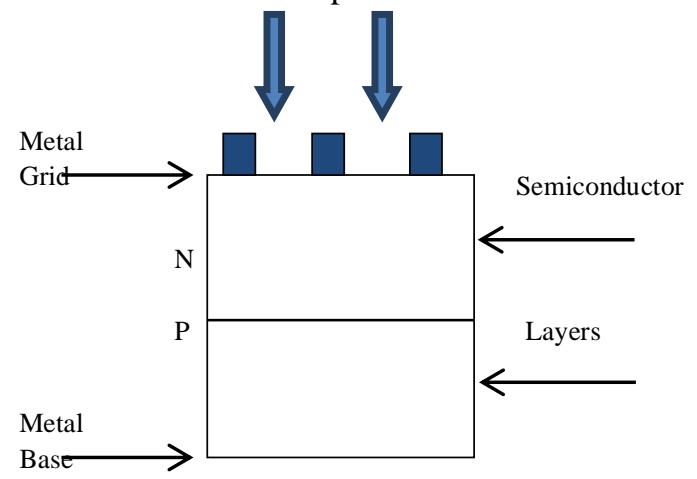




\section{IJOSTHE}

\section{ISSN: 2349-0772 | Volume 5 Issue 4 August 2018|www.ijosthe.com}

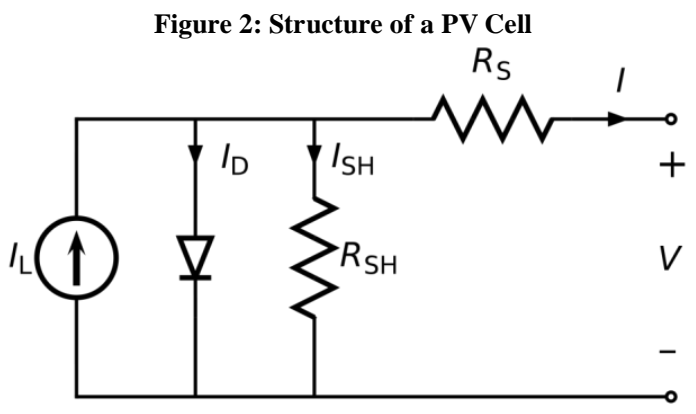

Figure 3: Simplified Circuit Diagram of a Solar PV Cell

$$
I_{o}=I_{P V}-I_{D}(V)-I_{S H}(V)
$$

Where (V) shows the dependency of diode current and resistor current to the terminal voltage whereas they're independent from irradiation value.

\section{Control Strategies}

The configuration of the split DC-link is shown in Fig.1.4. Since the neutral current of APFs only includes $\mathrm{AC}$ component and their fundamental components are quite small, the split DC-link topology can work well in these applications [10]. The implementation of this topology in three-level inverters is relatively simple. Moreover, it needs fewer semiconductors in comparison with other topologies [11]. However, it needs an expensive and a large capacitor to achieve equal voltage sharing between the split capacitors [12]. Another weakness with this configuration is that under severe unbalanced and non linear conditions, a large neutral current flows through the neutral path and cause a perturbation in the control scheme.

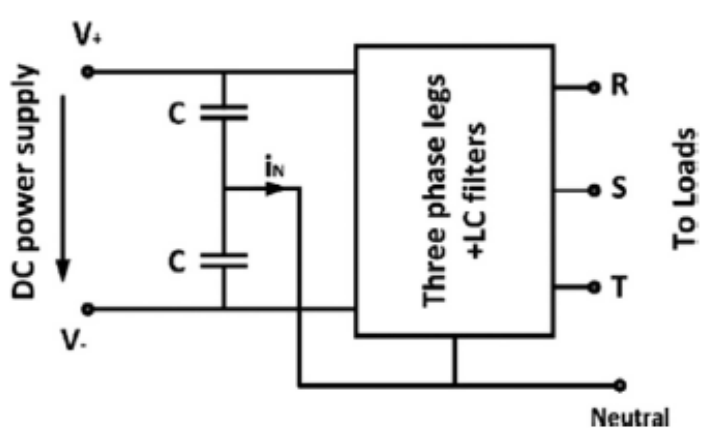

Figure 4: Three-phase inverter with split DC-link capacitors

Four-leg inverter Recently, researchers have shown an increasing interest in using the three - phase four leg inverters because of their capability to effectively handle the unbalanced loads in four-wire systems
$[13,14]$. In this topology, the neutral point is provided by connecting the neutral path to the midpoint of the additional fourth leg, as shown in Fig. 5. Although this configuration does not need to utilize large and expensive capacitors and provides lower ripple on the DC-link voltage, the use of two extra switches leads to a complicated control scheme.

It is generally concluded that the split DC-link is not appropriate for inverters, which supply power to possibly unbalanced loads in three-phase four-wire systems. On the other hand, the four-leg inverters have the significant potential to handle unbalanced and non-linear conditions.

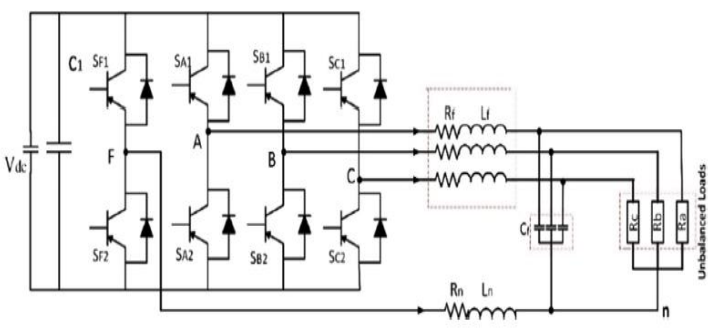

Figure 5: Topology of four-leg inverter

\section{Integral-resonant voltage control}

For a three-phase four-leg VSI the output voltage control system would be arranged by using an integral-resonant $(I+R)$ control structure as shown in Fig. 2. In order to control the duty-cycle of each phase (e.g. phase A as shown in Fig. 1.6) the firstharmonic voltage controller handles both the sinusoidal voltage reference, Vph_A_ref, and the actual voltage measured at the terminals of the output filter capacitors, Vph_A. The output voltage higher harmonic components would have their own reference values set to zero in order to achieve sinusoidal voltage waveform. As VSI operation under non-linear loads needs to be accomplished, harmonic compensators are required in the 


\section{IJOSTHE}

\section{ISSN: 2349-0772 | Volume 5 Issue 4 August 2018|www.ijosthe.com}

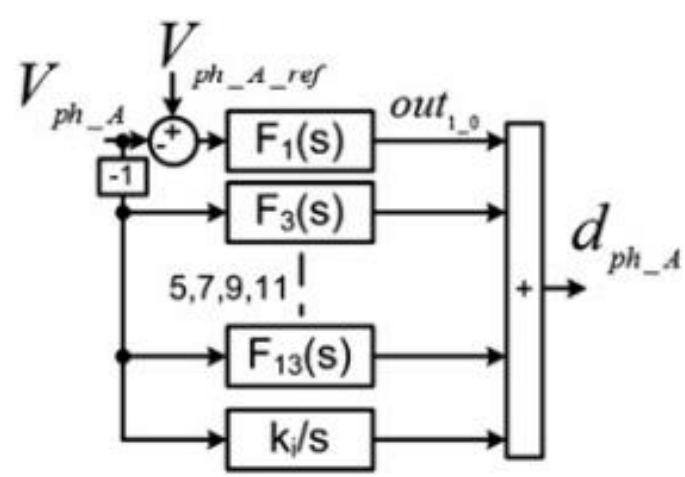

Figure 6: Block scheme of output phase A voltage control strategy

control algorithm. Hence, the transfer function F1 of the pure-resonant first-harmonic voltage controller would be as in (1), whereas the transfer function $\mathrm{Fx}$ for the $\mathrm{x}$-harmonic voltage controller would be written as in the following equations

$$
\begin{aligned}
& F_{1}=\frac{2 k_{i 1} \omega_{c 1} s}{s^{2}+2 \omega_{c 1} s+\omega_{0}^{2}} \\
& F_{x}=\frac{2 k_{i x} \omega_{c x} s}{s^{2}+2 \omega_{c x} s+\omega_{0 x}^{2}}
\end{aligned}
$$

\section{LITERATURE SURVEY}

M. Hasan et al [1] studies the effect of using non renewable energy resources. Although the country encourages utilizing renewable energy, the contribution is only around 3\%. Considering natural condition and geography, this country is blessed with great potential of renewable energy such as solar energy, wind energy, micro hydro and biomass energy. Noting the potential of renewable and sustainable energy resources in the country, the government must pay more attention on how to utilize it. Many efforts have been done to promote renewable energy such as to create energy policy and regulations, yet it still did not give any satisfactory result. Government, non-government agencies and the public should take a more proactive step to promote and use renewable energy in order to achieve the secure and environmentally sustainable energy resources.

E. W. Stein et al. [2] developed a model for decision-makers to rank various renewable and nonrenewable electricity production technologies according to multiple criteria. The model ranks electric power plants using wind, solar, geothermal, biomass, hydropower (i.e., renewable sources), nuclear, oil, natural gas and coal in terms of four comprehensive criteria clusters: financial, technical, environmental and socio-economic-political. The model was built using the Analytic Hierarchy Process (AHP) with empirical data from government and academic sources. The results indicate that wind, solar, hydropower and geothermal provide significantly more overall benefits than the rest even when the weights of the primary criteria clusters are adjusted during sensitivity analysis. results have implications for policy development and for decision makers in the public and private sectors. One conclusion is that financial incentives for solar, wind, hydropower and geothermal are sound and should be expanded

S. Semaoui et al [3] recommended a model of optimal sizing, to optimize the sizes of batteries capacity and photovoltaic (PV) generator for a standalone PV system without extra and with energy management of load. The recommended model was implemented in Matlab-Simulunk, takes into account the sub-models of the standalone PV system and the strategy of load management. This model uses two optimization criteria, the loss of power supply probability concept for the reliability and the energetic cost for the economic evaluation.

M. Z. Daud et al [6] presents an improved control strategy for a grid-connected hybrid PV/BES systems for mitigating PV farm output power fluctuations. A feedback controller for BES state of charge is proposed, where the control parameters are optimized using genetic algorithm (GA). GA-based multi objective optimization utilizes the daily average PV farm output power profile which was obtained from simulation using the historical PV system input data of Malaysia. In this way, the optimal size for the BES is also determined to hourly dispatch a $1.2 \mathrm{MW} \mathrm{PV}$ farm. A case study for Malaysia is carried out to evaluate the effectiveness of the proposed control scheme using PSCAD/EMTDC software package. Furthermore, the validation of results of the proposed controller and BES size on the actual PV system output data are also given

\section{PROPOSED OBJECTIVE}




\section{IJOSTHE}

\section{ISSN: 2349-0772 | Volume 5 Issue 4 August 2018|www.ijosthe.com}

The study of standalone system can be done by using a specific renewable energy resource like solar or wind. This simulated model can give us practical implications of the four leg inverter model. Further the changes in the modeling of gate pulses to the inverter can improve the output. These changes can lead to enhancement in the power out put of the energy source as well. We can also change the filter topology to bring a change in the distortion level

\section{CONCLUSION}

Renewable energy sources also called nonconventional type of energy are continuously replenished by natural processes. These systems are the right solution for a clean energy production. Using solar and wind power sources provide a realistic form of power generation. Here, a wind solar energy and fuel cell system with a converter topology can also be used which makes use of Boost Converter technology Enhanced Power output and smooth voltage waveform. Using LC filter can lead to reduced total harmonic distortion in the output voltage.

\section{REFERENCES}

[1] M. Hasan, T. Mahlia, and H. Nur, "A review on energy scenario and sustainable energy in Indonesia," Renewable and Sustainable Energy Reviews, vol. 16, pp. 2316-2328, 2012.

[2] E. W. Stein, "A comprehensive multi-criteria model to rank electric energy production technologies," Renewable and Sustainable Energy Reviews, vol. 22, pp. 640-654, 2013.

[3] S. Semaoui, A. H. Arab, S. Bacha, and B. Azoui, "Optimal sizing of a stand-alone photovoltaic system with energy management in isolated areas," Energy Procedia, vol. 36, pp. 358-368, 2013

[4] REN21, "Renewables Global Status Report 2014," available online at http://www.ren21.net/gsr.

[5] U. S. E. I. Administration, "Annual Energy Outlook 2014," available online at http://www.eia.gov/forecasts/aeo.

[6] M. Z. Daud, A. Mohamed, and M. Hannan, "An improved control method of battery energy storage system for hourly dispatch of photovoltaic power sources," Energy Conversion and Management, vol. 73, pp. 256-270, 2013.

[7] S. Teleke, M. E. Baran, S. Bhattacharya, and A. Q. Huang, "Rule-based control of battery energy storage for dispatching intermittent renewable sources," Sustainable Energy, IEEE Transactions on, vol. 1, pp. 117-124, 2010.

[8] S. Koohi-Kamali, V. Tyagi, N. Rahim, N. Panwar, and H. Mokhlis, "Emergence of energy storage technologies as the solution for reliable operation of smart power systems: a review," Renewable and Sustainable Energy Reviews, vol. 25, pp. 135-165, 2013.

[9] N. S. Hasan, M. Y. Hassan, M. S. Majid, and H. A. Rahman, "Review of storage schemes for wind energy systems," Renewable and Sustainable Energy Reviews, vol. 21, pp. 237-247, 2013
[10] Meersman B, Renders B, Degroote L, Vandoorn T, De Kooning, Vandevelde L. Overview of three-phase inverter topologies for distributed generation purposes. In: Proceedings of the $2^{\text {nd }}$ international conference on innovation for sustainable production;2010,April.pp.18-21.

[11] Cortes P, OrtizG, YuzJ, Rodriguez J,VazquezS, FranqueloL. Model predictive control of an inverter with output LC filter for UPS applications. IEEE TransIndElectron 2009;56(6):1875-83.

[12] Liang J, GreenT, FengC, WeissG. Increasing voltage utilization in split-link, four-wireinverters. IEEE Trans Power Electron2009;24(6):1562-9.

[13] Zhang R,PrasadH, Boroyevich D,LeeFC.Lee. Threedimensional space vector modulation for four-leg voltagesource converters. IEEE Trans Power Electron 2002;17(3):314-26.

[14] Lohia P,MishraM, KarthikeyanK, VasudevanK. Aminimally switched control algorithm for three-phase four-leg VSI topology to compensate unbalanced and non linear load. IEEE Trans Power Electron2008;23(4):1935-44. 